\title{
A modified experimental model of malignant pleural disease induced by lung Lewis carcinoma (LLC) cells
}

\author{
Milena Marques Pagliarelli Acencio', Juliana Puka1', Evaldo Marchi,2, Leila Antonangelo 1,3, \\ Ricardo Mingarini Terra ${ }^{4}$, Francisco Suso Vargas ${ }^{1}$, Vera Luiza Capelozzi ${ }^{1}$ and Lisete Ribeiro Teixeira ${ }^{*}$
}

\begin{abstract}
Background: Malignant pleural effusion resulting mainly from pleural metastases of lung adenocarcinoma has clinical relevance, being a sign of poor prognosis and low life expectancy. Experimental models can mimic the human condition, contributing to advances in current understanding of the mechanisms patients' pleural fluid accumulation and possible therapeutic strategies. The objective of this study is to evaluate the role of different concentrations of Lewis lung carcinoma cells (LLC cells) at the time of induction of experimental MPE and the main effects on survival of animals.

Methods: C57BL/6 mice received intrapleural injection of $0.1,0.5$ or $1.5 \times 10^{5}$ LLC cells and survival curve, biochemical and pathological analyses of pleural fluid and tissue were analyzed.

Results: Evaluation of weight loss, mobility and survival showed that animals that received $0.5 \times 10^{5}$ cells maintained more stable condition up to day 14 and a gain of 6 days survival over mice that received the highest concentration.

Conclusion: This study may allow a better understanding the mechanisms involved in the development of malignant pleural effusion and it may be promising in evaluating therapy to avoid recurrence, as the best time to indicate pleurodesis or target therapies.
\end{abstract}

Keywords: Lewis lung carcinoma, Malignant pleural effusion, Lung cancer

\section{Background}

Malignant pleural effusion (MPE) resulting from pleural metastasis of lung adenocarcinoma is a common clinical problem with severe implications, since it is a debilitating condition associated with high morbidity, poor prognosis and low life expectancy (3-15 months) [1-6]. Approximately $15 \%$ of lung cancer patients present pleural effusion at the time of diagnosis and half of them develop pleural effusion at disease advanced stages [1-5].

Current therapeutic options for MPE are limited to treatment of the primary tumor and pleural cavity drainage with or without pleurodesis, practices that can cause

\footnotetext{
*Correspondence: lisetepneumo@yahoo.com.br

1 Pleura Laboratory, Pulmonary Division, Heart Institute (InCor), University of Sao Paulo Medical School, Rua Dr. Eneas de Carvalho Aguiar, 44,

Cerqueira César, São Paulo Zip code: 05403-000, Brazil

Full list of author information is available at the end of the article
}

pain and discomfort, carry risks of adverse effects, and do not benefit a substantial portion of patients [7-14].

For a long time, the pathogenesis of MPE has been poorly understood, but substantial progress has been made over the past few years facilitated by the use of animal models [15-19]. These models can mimic the human condition, contributing to advances in current understanding of the mechanisms patients' pleural fluid accumulation and possible therapeutic strategies [19-27].

The objective of this study is to evaluate the role of different concentrations of Lewis lung carcinoma cells (LLC cells) at the time of induction of experimental MPE and the main effects on survival of animals.

The increase of survival time and delaying systemic effects, a better and more detailed understanding of the mechanisms involved in the development of malignant pleural effusion can be gained. This would facilitate 
future studies making a better assessment of therapeutic response possible.

\section{Methods}

\section{Cell culture}

The Lewis lung carcinoma (LLC) cells were purchased from the American Type Culture Collection (Manassas, VA, USA) and were cultured at $37{ }^{\circ} \mathrm{C}$ in $5 \% \mathrm{CO}_{2}{ }^{-} 95 \%$ air using Dulbecco's modiWed Eagle's medium (DMEM) with $10 \%$ fetal bovine serum.

\section{Animal model}

One hundred and thirty male (6-8 weeks old) C57BL/6 mice (obtained from Laboratory Animal Center of Faculty of Medicine of University of São Paulo) were acclimatized for 1 week. All animal care and experimental procedures were approved by the University Ethics Committee (CEUA/CAPPesq).

Animals were anesthetized using $35 \mathrm{mg} / \mathrm{kg}$ of ketamine hydrochloride (Cristalia, Brazil) and $5 \mathrm{mg} / \mathrm{kg}$ of xylazine hydrochloride (Bayer, Brazil) prior to all procedures. The right chest was cleansed with an alcohol solution (Rioquimica, Sao Paulo, Brazil). The intrapleural injection was performed using a 23-gauge needle attached to a 1-mL syringe containing the solution of cells which was introduced into the chest cavity at $1 \mathrm{~cm}$ lateral to the right parasternal line. The plunger of the syringe was removed and the needle was slowly advanced until it reached the pleural space, where the sub-atmospheric intrapleural pressure allowed the fluid to enter the pleural cavity spontaneously. The mice were monitored after the procedure until they were completely recovered.

Three groups of 40 mice each received concentrations of LLC at $0.1,0.5$ or $1.5 \times 10^{5}$ cells intrapleurally. These animals were subdivided into two groups; the first (30 animals per concentration of cells) were euthanized after 7,14 or 21 days and the second group (10 animals per concentration of cells) were evaluated for survival expectancy. A control group of 10 animals received saline solution intrapleurally.

Mice were killed according to the study calendar; the abdominal wall was opened and the viscera were retracted to visualize the diaphragm. Pleural fluid (PF), when present, was gently aspirated and the volume was measured and placed in tubes for evaluation.

\section{Weight, mobility and survival analysis}

After the procedure all animals were observed until complete recovery and they were evaluated for weight $(\mathrm{g})$ and mobility by a subjective score of $0-3(0=$ normal and $3=$ stillness). We monitored mortality daily for all groups to obtain the survival curve.

\section{Histological assays}

After 7,14 or 21 days the thorax was dissected and removed en bloc. A small amount of $10 \%$ formaldehyde was injected through the trachea to keep the lungs expanded and the entire block plus kidney, liver and spleen were placed in $10 \%$ formaldehyde. After at least $24 \mathrm{~h}$ in formaldehyde, the pleural cavities were opened and exposed through longitudinal chest incisions at the mid-clavicular lines. Tissues were fixed in $10 \%$ neutrally buffered formalin for $24 \mathrm{~h}$ and $70 \%$ ethanol for 3 days. In sequence, they were embedded in paraffin, and $5-\mu \mathrm{m}$ thick slices were cut, mounted on slides and stained with hematoxylin and eosin (H\&E).

\section{Biochemical assays}

Lactic dehydrogenase (kinetic UV method) and total protein (Biuret method) were quantified in the pleural fluid using commercial kits (Wienner, Argentina) and analyzed in semi-automatic device.

\section{Cytology}

Pleural fluid cells were counted in a Neubauer chamber. After centrifugation, cells cytospin were prepared and the slides were air dried and stained using Leishman staining to determine the cell differential.

\section{Statistics}

The results are presented as mean and standard deviation. Comparisons among the groups were performed using ANOVA followed by the comparison multiple test. For the survival time, Kaplan-Meier curves were established for each group and the times were compared using a log-rank test. A value of $p<0.05$ was considered significant. SigmaStat 3.1 (Systat, CA, USA) was used for the analyses.

\section{Results}

After the intrapleural injection of different concentrations of LLC cells, all animals presented tumor implantation with development of malignant pleural effusion showing differences among them according to the time and stage of disease. Free-floating bilateral pleural effusions and pleural tumor foci were clearly visible through the diaphragm. Interestingly, in the majority of mice that received $0.1 \times 10^{5}$ cells, minimal or absence of pleural fluid and few tumoral implants were observed until the 14th day.

Evaluation of body weight and mobility showed that mice in the group of $1.5 \times 10^{5}$ cells had reduced weight and mobility after 14 days while in the other groups, these differences were noted only after 21 days $(\mathrm{p}<0.05)$.

In the survival analysis, pleural carcinomatosis was lethal in all groups. In the group of highest concentration 
$\left(1.5 \times 10^{5}\right.$ cells $)$ the mortality was $100 \%$ on the 19 th day while the groups of 0.5 and $0.1 \times 10^{5}$ cells showed maximum survival of 25 and 27 days, respectively (Fig. 1).

Pleural fluid volume was measured at 7, 14 and 21 days. The volume was increasing significantly according to the time and LLC cells concentration $(\mathrm{p}<0.05)$; group $0.1 \times 10^{5}$ cells showed pleural effusion only after 14 days in few animals and for group $1.5 \times 10^{5}$ cells, evaluation was only possible up to the 14th day (all animals died by day 19) (Fig. 2). In the control group (saline intrapleurally), we do not observe pleural fluid accumulation.

The macroscopic aspect of most pleural fluid was hemorrhagic (but did not coagulate). By harvesting mice at serial time points we observed that malignant pleural effusion was formed gradually and that their red blood cell content increased stepwise.

Total cells count was progressively increasing up to 14 day being more evident in highest concentrations $(0.5$ and $1.5 \times 10^{5}$ ) (Fig. 2). MPE differential cells revealed a mixed inflammatory infiltrate interspersed with malignant cells. The inflammatory cell population consisted of mononuclear cells (60\%), lymphocytes (20\%) and neutrophils $(10 \%)$. Mesothelial cells accounted for less than $1 \%$ of cells.

Pleural fluid LDH levels were higher proportional to the time $(\mathrm{p}<0.001)$ and concentration $(\mathrm{p}<0.05)$ of injected LLC cells. Protein levels were similar among groups excepted at 7 days in $0.1 \times 10^{5}$ LLC cells group (Fig. 2).

Tumor implants in the pleura were evident earlier in groups that received a larger concentration of LLC cells. The presence of loose tumors in the pleural space was also noted in all study groups at 7 days except in the group with the lowest concentration of LLC cells. Larger pleural tumors formed bridges between the lung parenchyma and the thoracic cage and infiltrated neighboring anatomic structures, including the chest wall, mediastinum, and diaphragm (Fig. 3). In group $1.5 \times 10^{5} \mathrm{LLC}$ cells numerous tumor implants were observed in the visceral and parietal pleura after 7 days of exposure. In group $0.5 \times 10^{5}$ cells LLC we noted few dispersed implants at day 7 with more pronounced implantation after 14 days. In animals receiving lower cells concentration, tumor implants were only observed after 14 days (Fig. 3).

Neoplastic infiltration of lung parenchyma was observed only in few animals with no correlation with the dose or exposure time. However, lung parenchymal inflammation was unremarkable in all groups over all check points; there was no inflammatory focus at concentration $0.1 \times 10^{5}$ cells on day 7 .

Histological evaluation of pericardium and heart muscle showed tumor implants in the first 7 days after injection of $1.5 \times 10^{5}$ LLC cells with increased progression over time. In the other concentrations few tumor implants were observed during the study (Fig. 4).

In the liver, micro foci of steatosis were observed after 14 days at concentrations 1.5 and $0.5 \times 10^{5}$ LLC cells. No relevant histological changes were observed in the renal evaluation. Hyperplasia of the white pulp of the spleen was observed at all evaluation time points with greater evidence at concentrations of 1.5 and $0.5 \times 10^{5}$ LLC cells (Fig. 4).

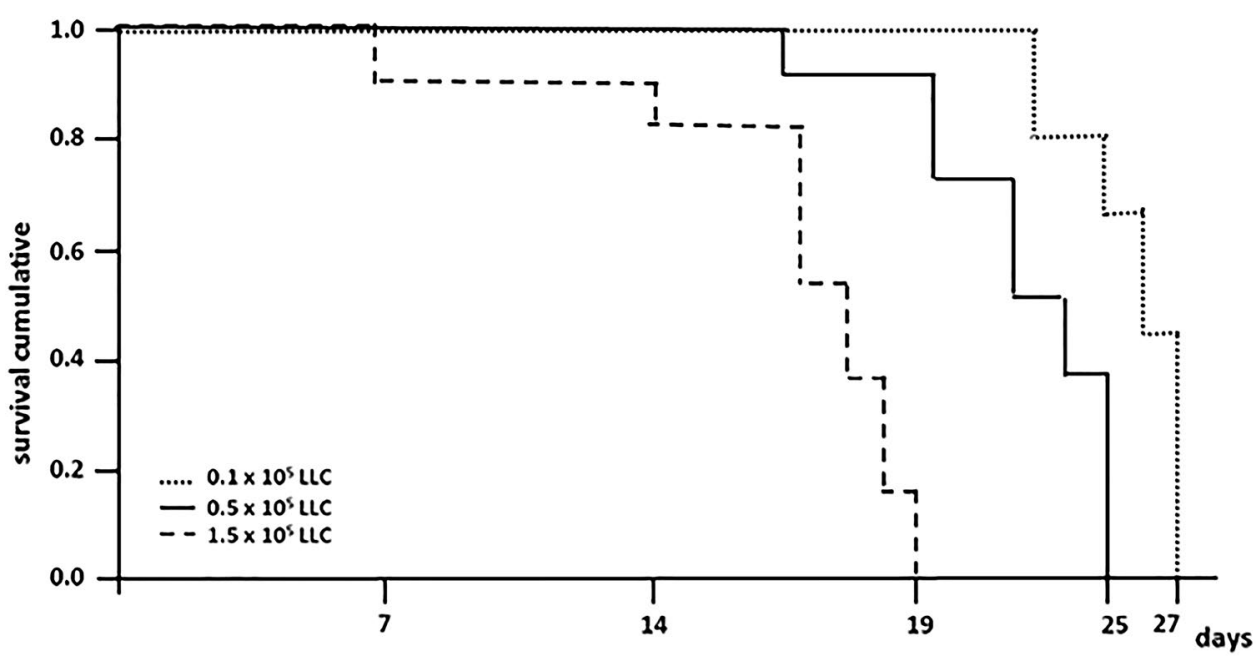

Fig. 1 Mice survival time evaluation with intrapleural injection of $0.1,0.5$ or $1.5 \times 10^{5}$ LLC cells 


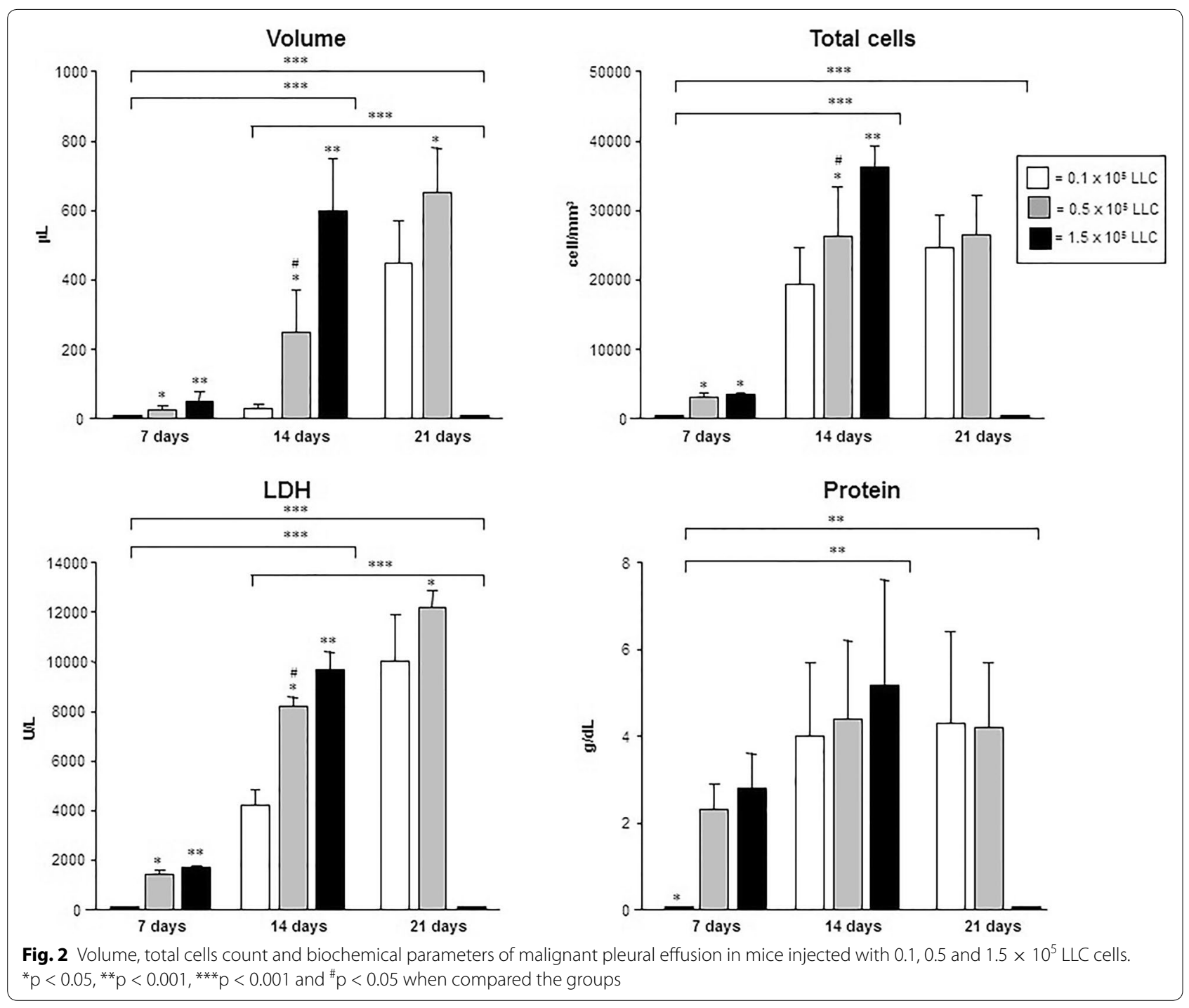

\section{Discussion}

This study evaluated the survival curve, laboratorial and histological aspects in an experimental murine model of MPE using different concentrations of LLC cells. Evaluation of weight loss, mobility and survival at the higher concentrations ( 0.5 and $1.5 \times 10^{5}$ cells) showed that animals that received $0.5 \times 10^{5}$ cells maintained more stable condition up to day 14 . The survival curve shows a gain of 6 days survival over mice that received the highest concentration. We found MPE from day 7 and several tumor foci in both the visceral and parietal pleura in the higher concentration groups. However, minimal or no volume of pleural fluid and few implants were observed in the smaller LLC concentration group at day 14 .

Lung cancer is the most common cause of worldwide cancer-related mortality, leading to over a million deaths each year and adenocarcinoma is its most common histological type [1-5]. In this scenario, MPE resulting mainly from pleural metastases of lung adenocarcinoma has clinical relevance $[4,14]$. Its emergence is a sign of poor prognosis and low life expectancy, as it indicates that the tumor is incurable by surgery [4]. Dyspnea occurs in more than $50 \%$ of patients, severely compromising their quality of life. In spite of the therapeutic advances since the platinum-based schemes, lung cancer treatment does not significantly impact the disease evolution of most patients [4-14].

New therapeutic strategies are needed to improve local control and the spread of cancer, but this requires greater insight into the pathogenesis of this disease.

Until some time ago, there were a few experimental models for the study of pleural neoplasms, most using 

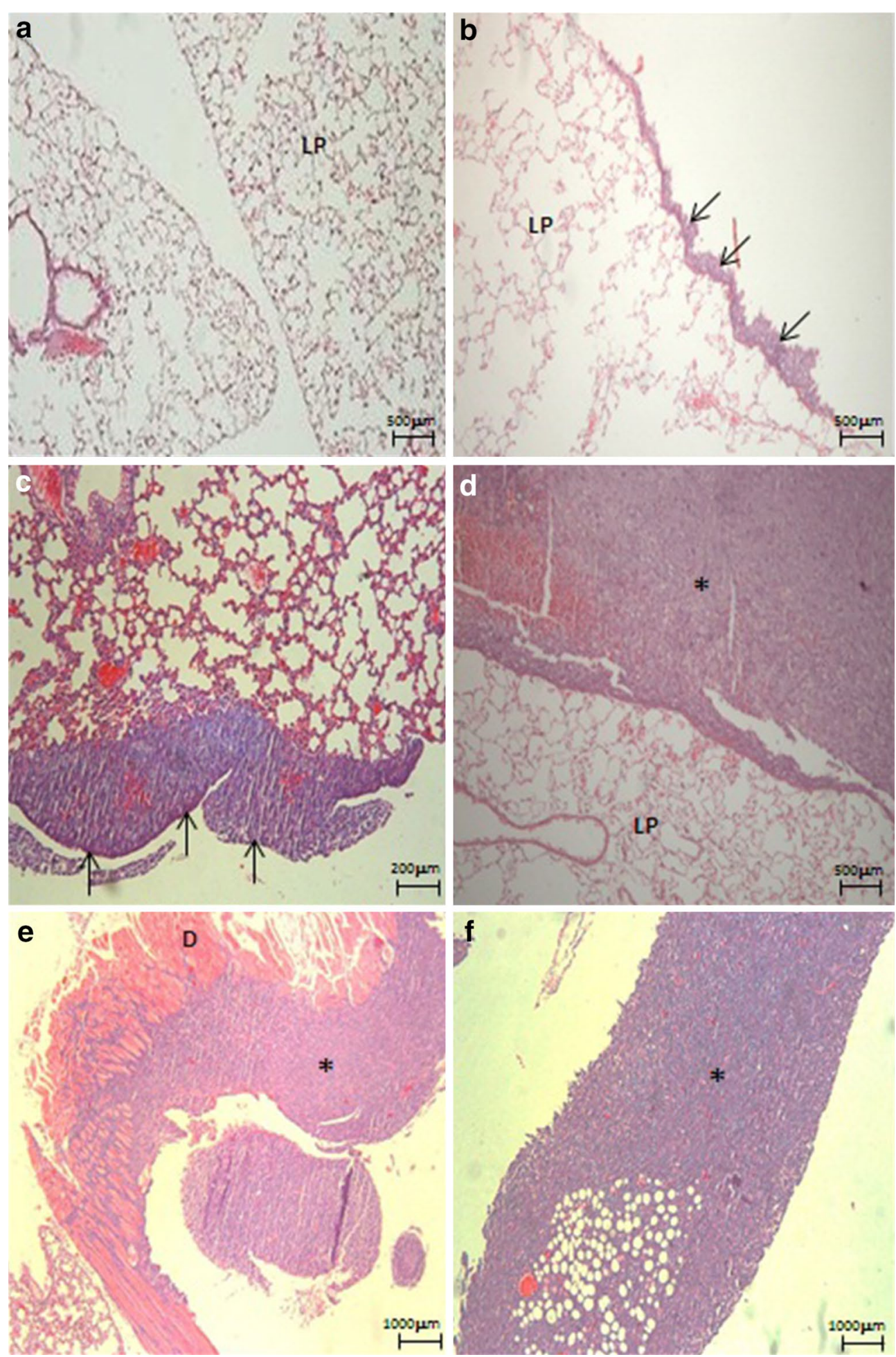

Fig. 3 Histology of pleura, lung parenchyma and diaphragm of mice that received intrapleural injection of LLC cells. a Pleura and lung parenchyma after 7 days of $0.1 \times 10^{5}$ cells; $\mathbf{b}$ tumor implantation in visceral pleura after 7 days of $0.5 \times 10^{5}$ cells (arrows); c tumor implants in visceral pleura after 14 days of $0.5 \times 10^{5}$ cells (arrows); d tumor implants in visceral pleura after 14 days of $1.5 \times 10^{5}$ cells (asterisk); e massive tumor invading diaphragm after 14 days of $1.5 \times 10^{5}$ cells (asterisk); f tumor mass observed after 21 days of LLC cells (asterisk). Hematoxylin \& eosin staining. LP lung parenchyma, asterisk tumor, arrows tumor implants 

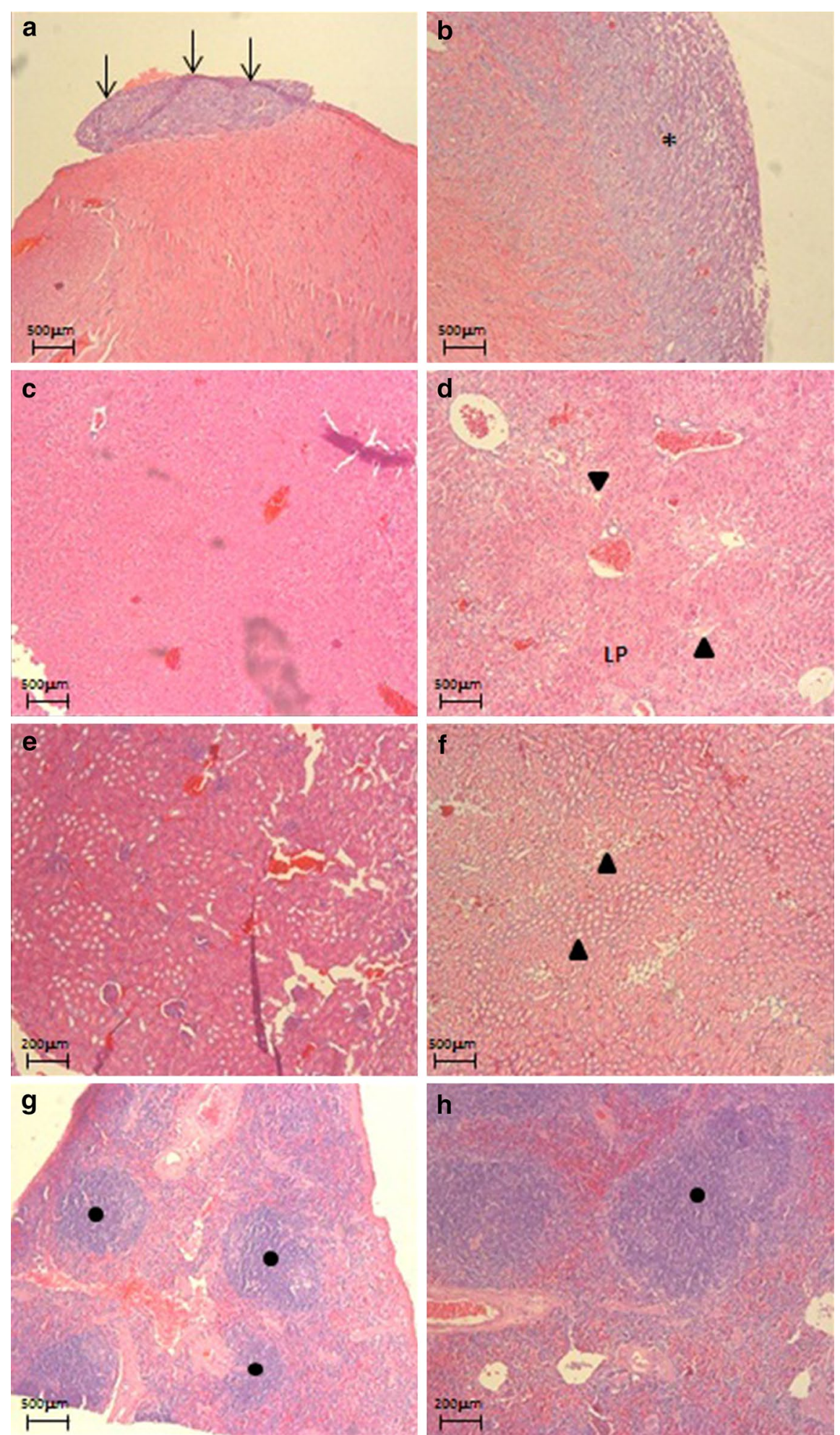

Fig. 4 Histology of organs of mice that received intrapleural injection of LLC cells. a Tumor implants in pericardium after 7 days of $1.5 \times 10^{5}$ cells (arrows); b neoplastic cells infiltrating the myocardium (asterisk) after 14 days of $1.5 \times 10^{5}$ cells; c normal liver after 7 days of $0.5 \times 10^{5}$ cells; $\mathbf{d}$ liver with steatosis (filled triangle) after 14 days of LLC cells; $\mathbf{e}, \mathbf{f}$ kidney with tubular steatosis (filled triangle) and without neoplastic cells after 7 or 14 days. g, h Reactive spleen (filled circle) without neoplastic cells after 7 and 14 days. Hematoxylin \& eosin staining 
animals with normal pleura to test palliative therapies such as pleurodesis [24-26]. In the absence of malignant disease assessment of the natural evolution of the cancer, neoplasia-host interactions, or possible immune response is obviously not possible [25, 26]. Therefore, some researchers have developed novel models of MPE with a more accurate mimicry of the human condition. These models have contributed to significant advances in the understanding of fluid exudation induced by cancer metastasis to the pleura [19]. They have yielded novel insights into the pathogenesis of adenocarcinoma as well as into the mechanisms of intrapleural malignant effusion accumulation, tumor dissemination and possible therapeutic targets to block pleural effusion [19].

In 2006, Stathopoulos et al. developed and characterized a novel mouse model of malignant pleural effusion by injecting $1.5 \times 10^{5}$ Lewis lung carcinoma (LLC) cells directly into the pleural space of immunocompetent C57BL/6 mice [20].

LLC cells are derived from a spontaneously arising lung adenocarcinoma in C57BL/6 mice. These cells are characterized by short doubling times in vitro and in vivo and aggressive biological behavior [19-21]. The cells can be propagated in C57BL/6 mice, giving rise to lung adenocarcinoma and human-like MPEs producing exudates with high protein and LDH content, as well as high levels of VEGF and monocyte chemoattractant chemokines [19-21].

This LLC-C57BL/6 model is highly reproducible since it uses immunocompetent animals, closely resembles human MPEs and provides reproducible end-points. It can be used to study the influence of specific host and tumor factors on the pathogenesis of MPE and to evaluate new therapeutic strategies. In addition, all of the animals get MPE and intense tumor foci on visceral and parietal pleura in 14 days [20].

Nevertheless, the maximum survival of the animals in the Stathopoulos et al. model was 17 days, an unfavorable point, since survival is an important outcome measure and so few days may not be sufficient to assess outcome $[20,21]$

Also, in these studies authors observed a correlation between the number of pleural tumor foci and the volume of pleural fluid. They discussed the importance of the host immune response, which is partly responsible for the malignant pleural fluid accumulation [20-23]. These issues are directly relevant in studies to investigate the pathogenesis and treatment of MPEs. The pleural fluid accumulation remains the primary end-point in this model; however, determinations relevant to these bioprocesses may serve as additional end-points in animal models of MPE.
The cellular and biochemical profile of pleural effusion resulting from induced lung adenocarcinoma mimics human MPE, which is high in protein and LDH levels and nucleated cells with neoplastic cells permeating a rich inflammatory infiltrates. Implantation and growth of pleural tumors triggers a host inflammatory response characterized by a mixed inflammatory cell influx into the pleural fluid, angiogenesis, and vascular hyperpermeability, all fundamental steps in MPE pathogenesis [19-21].

We found tumors implants in the visceral and parietal pleura in all groups studied and they were proportional to the concentration and time from instillation of LLC cells. Metastasis to the pericardium was more evident at the highest concentration. Inflammatory lung parenchyma cells and histological changes in the liver, kidneys and spleen were observed in all groups with the highest scores in groups 0.5 and $1.5 \times 10^{5}$ cells.

Furthermore, induction of MPE in animals leads to cachexia, which can serve as a surrogate marker of tumor progression. In our study mice that received $0.5 \times 10^{5}$ LLC cells maintained more stable condition through day 14 compared to mice that received the highest concentration, resulting in a longer survival.

One limitation of our study was related to the assessment of animals at 21 days due to the fact that most died before analysis could be done.

\section{Conclusions}

Our results show that using a dose of $0.5 \times 10^{5}$ cells LLC is possible not only to induce the disease as well as to better evaluate survival time, without prejudice to the model proposed initially by Stathophoulous and colleagues [20]. With this cell concentration we obtained a model that allowed for monitoring longer survival, the study of pleuropulmonary changes and to assess local and distant metastases, opening a fantastic range of study opportunities.

This study may allow a better understanding the mechanisms involved in the development of malignant pleural effusion. In addition, it may be promising in evaluating therapy responses, the best time to indicate pleurodesis, as well as, to consider the response to immunomodulatory therapies, costs and benefits of targeted therapies.

\section{Authors' contributions}

LRT contributed to the conception and design of the study, acquisition of the data, statistical analysis and interpretation of the data, writing and final review of the manuscript. MMPA: responsible to development of methodology and execution of experimental and laboratorial techniques, interpretation of the data and writing the manuscript. EM: contributed to the conception and design of the study, critical revision of the manuscript for important intellectual content. LA: cytological analysis and critical revision of the manuscript for important intellectual content. JP: execution of experimental techniques; revision of manuscript and references. RMT: statistical analysis and revision of manuscript. FSV: critical revision of the manuscript for important intellectual 
content. VLC: pathological analysis and critical revision of the manuscript for important intellectual content. All authors read and approved the final manuscript.

\section{Author details \\ 1 Pleura Laboratory, Pulmonary Division, Heart Institute (InCor), University of Sao Paulo Medical School, Rua Dr. Eneas de Carvalho Aguiar, 44, Cerqueira César, São Paulo Zip code: 05403-000, Brazil. ${ }^{2}$ Medical College of Jundiai, São Paulo, Brazil. ${ }^{3}$ Clinical Laboratory and LIM 03, Department of Pathology, Hospital das Clínicas, University of Sao Paulo Medical School, São Paulo, Brazil. ${ }^{4}$ Division of Thoracic Surgery, Heart Institute (InCor), University of São Paulo Medical School, São Paulo, Brazil.}

\section{Acknowledgements}

We thank biologists Carlos SR Silva and Vanessa A Alvarenga for their assistance with animal care and sample preparation and storage. Financial support: Research Support Foundation of the State of São Paulo (FAPESP \# 2013/111489) and the National Research Council (CNPq), Brazil.

\section{Compliance with ethical guidelines}

\section{Competing interests}

The authors declare that they have no competing interests.

Received: 21 May 2015 Accepted: 7 September 2015

Published online: 15 September 2015

\section{References}

1. Alberg AJ, Samet JM. Epidemiology of lung cancer. Chest. 2003;123:21-49.

2. Sugiura S, Ando Y, Minami H, Ando M, Sakai S, Shimokata K. Prognostic value of pleural effusion in patients with nonsmall cell lung cancer. Clin Cancer Res. 1997;3:47-50.

3. Rodriguez-Panadero F, Borderas Naranjo F, Lopez-Mejias J. Pleural metastatic tumours and effusions: frequency and pathogenic mechanisms in a post-mortem series. Eur Respir J. 1989;2:366-9.

4. Morgensztern D, Waqar S, Subramanian J, Trinkaus K, Govindan R. Prognostic impact of malignant pleural effusion at presentation in patients with metastatic non-small-cell lung cancer. J Thorac Oncol. 2012;7:1485-9.

5. Light RW. Pleural diseases. New York: Lippincott Willians and Wilkins; 2007. p. 108-34

6. Sahn SA. Malignant pleural effusion. Eur Respir Mon. 2002;22:177-88.

7. Antony VB, Loddenkemper R, Astoul P, Boutin C, Goldstraw P, Hott J, Rodriguez-Panadero F, Sahn SA. Management of malignant pleural effusions. Eur Respir J. 2001;18:402-19.

8. Gary-Lee YC, Light RW. Management of malignant pleural effusions. Respirology. 2004;9:148-56.

9. Neragi-Miandoab S. Malignant pleural effusion, current and evolving approaches for its diagnosis and management. Lung Cancer. 2006;54:1-9

10. Heffner JE, Klein JS. Recent advances in the diagnosis and management of malignant pleural effusions. Mayo Clin Proc. 2008;83:235-50.
11. Uzbeck MH, Almeida FA, Sarkiss MG, Morice RC, Jimenez CA, Eapen GA, Kennedy MP. Management of malignant pleural effusions. Adv Ther. 2010;27:334-47.

12. Roberts ME, Neville E, Berrisford RG, Antunes G, Ali NJ. Management of a malignant pleural effusion: British Thoracic Society pleural disease guideline 2010. Thorax. 2010;65:32-40.

13. Musani Al. Treatment options for malignant pleural effusion. Curr Opin Pulm Med. 2009;15:380-7.

14. Felip E, Gridelli C, Baas P, Rosell R, Stahel R, Panel Members. Metastatic nonsmall-cell lung cancer: consensus on pathology and molecular tests, first-line, second-line, and third-line therapy. 1st ESMO consensus conference in lung cancer (Lugano 2010). Ann Oncol. 2011;22:1507-19.

15. Jantz MA, Antony VB. Pathophysiology of the pleura. Respiration. 2008;75:121-33

16. English JC, Leslie KO. Pathology of the pleura. Clin Chest Med. 2006;27:157-80.

17. Antony VB. Immunological mechanisms in pleural disease. Eur Resp J. 2003;21:539-44.

18. Mutsaers SE. Mesothelial cells: their structure, function and role in serosal repair. Respirology. 2002;7:171-91.

19. Stathopoulos GT, Kalomenidis I. Animal models of malignant pleural effusion. Curr Opin Pulm Med. 2009:15:343-52.

20. Stathopoulos GT, Zhu Z, Everhart MB, Kalomenidis I, Lawson WE, Bilaceroglu S, Peterson TE, Mitchell D, Yull FE, Light RW, Blackwell TS. Nuclear factor-kappaB affects tumor progression in a mouse model of malignant pleural effusion. Am J Respir Cell Mol Biol. 2006;34:142-50.

21. Psallidas I, Karabela SP, Moschos C, Sherrill TP, Kollintza A, Magkouta S, Theodoropoulou P, Roussos C, Blackwell TS, Kalomenidis I, Stathopoulos GT. Specific effects of bortezomib against experimental malignant pleural effusion: a preclinical study. Mol Cancer. 2010;9:56.

22. Stathopoulos GT. Translational advances in pleural malignancies. Respirology. 2011;16:53-63.

23. Stathopoulos GT, Kalomenidis I. Malignant pleural effusion: tumor-host interactions unleashed. Am J Respir Crit Care Med. 2012;186:487-92.

24. Guo YB, Kalomenidis I, Hawthorne M, Parman KS, Lane KB, Light RW. Pleurodesis is inhibited by anti-vascular endothelial growth factor antibody. Chest. 2005;128:1790-7.

25. Teixeira LR, Vargas FS, Acencio MM, Ribeiro SC, Sales RK, Antonangelo L, Marchi E. Blockage of vascular endothelial growth factor (VEGF) reduces experimental pleurodesis. Lung Cancer. 2011;74:392-5.

26. Ribeiro SCC, Vargas FS, Antonangelo L, Marchi E, Genofre EH, Acencio MMP, Teixeira LR. Monoclonal anti-vascular endothelial growth factor antibody reduces fluid volume in an experimental model of inflammatory pleural effusion. Respirology. 2009;14:1188-93.

27. Wang Y, Yao Y, Liu H, Ma X, Lv T, Yuan D, Xiao X, Yin J, Song Y. Itraconazole can inhibit malignant pleural effusion by suppressing lymphangiogenesis in mice. Transl Lung Cancer Res. 2015;4:27-35.

\section{Submit your next manuscript to BioMed Central and take full advantage of:}

- Convenient online submission

- Thorough peer review

- No space constraints or color figure charges

- Immediate publication on acceptance

- Inclusion in PubMed, CAS, Scopus and Google Scholar

- Research which is freely available for redistribution 